\section{AL-AZHAR}

Assiut Dental Journal
The Official Publication of The

Faculty of Dental medicine.

Al-Azhar Assiut Uniuersity.

AADJ, Vol. 2, No. 2, October (2019) - PP. 177:183

ISSn 2682-2822

\title{
Evaluation of the Efficacy of Surgically-Assisted Clear-Aligners in Orthodontic Tooth Movement Acceleration
}

\author{
Abd El-Ghafar I.S. ${ }^{* 1}$, El-Sayed S.A. ${ }^{1}$, Abd El-Monem M.M. ${ }^{1}$
}

Codex : 20/1910

Aadj@azhar.edu.eg

\section{KEYWORDS}

Clear aligners , crowding, orthodontic ,tooth movement, surgical assissted.

1. Department of Orthodontics, Faculty of Dental Medicine, Al-Azhar University, Assiut, Egypt

* Corresponding Author e-mail: ibrahemsaad1114@azhar.edu.eg

\begin{abstract}
Aim: To evaluate the efficacy of surgically-assisted clear-aligners in orthodontic tooth movement acceleration. Subjects and Methods: This study was carried out upon 14 patients with an age range from 15 to 25 years, Patients who met the inclusion criteria were randomly assigned to the control group in which patients were treated by clear aligners alone and study group in which patients were treated by clear aligners assisted with surgery. Results: The collected data were analysed and revealed that there was a statistically significant difference between the control group and the experimental group where $(p<0.001)$. The highest mean value of the total treatment time was found in the control group, while the least mean value was found in the study group. Conclusion: The results of this study suggested that the overall treatment time needed to alleviate crowding in the control and study groups was significantly different with a drastic decrease in orthodontic treatment time in the study group.
\end{abstract}

\section{INTRODUCTION}

Orthodontics is both an art and a science. The quest for beauty and balance in appearance is art. Putting a plier to a wire at each appointment to attain that perfect treatment outcome is analogous to putting a brush to canvas and seeing a painting come to life. Both are dependent on the knowledge and vision of the expert. ${ }^{1}$

To address the increasing aesthetic demand for an alternative to conventional braces, investigators have developed several solutions, such as ceramic or composite braces, lingual orthodontics, and clear aligners. $^{2}$

Esthetic orthodontic treatment with removable, clear, semi-elastic polyurethane aligners has become an increasingly common treatment choice since its first appearance in 1997. This computer-aided modeling technique facilitates the fabrication of numerous aligners to move teeth with relative precision to obtain a good occlusion. These aligners are 
made from a thin, transparent plastic that fits over the buccal, lingual/palatal, and occlusal surfaces of the teeth. ${ }^{3,4}$ Removable clear aligners have become a popular treatment choice for clinicians because of their esthetics, comfort, and better oral hygiene compared with traditional appliances, although their use is limited to selected cases. Nowadays, in addition to the esthetic demands, patients require a reduced orthodontic treatment time..$^{5}$

Attempts to shorten the time needed for tooth movement can be divided into three categories: ${ }^{6-8}$

1. Local administration of chemicals,

2. Physical or mechanical stimulation of the alveolar bone, such as the use of direct electrical current or magnets, and (3) Surgery, including dental distraction and alveolar corticotomies.

A recent studies evaluating the effectiveness of interventions on accelerating orthodontic tooth movement with a conventional orthodontic appliances suggested that corticotomy is a relatively safe and effective means of doing so. It has been suggested that the biologic basis of corticotomyassisted orthodontic treatment is mediated by a regional acceleratory phenomenon (RAP). Further, it has been hypothesized that corticotomy can lead to intensified osteoclastic activity, resulting in osteopenia and increased bone remodeling. The consequent accelerated tooth movement should shorten treatment duration. ${ }^{5}$

The aim of the present study was to evaluate the efficacy of clear-aligners that combined with surgery in orthodontic tooth movement acceleration.

\section{PATIENTS AND METHODS}

This study was carried out upon 14 patients with an age range from 15 to 25 years, selected from the outpatient orthodontic clinic, Faculty of Dental medicine, Al-azher University, Assiut branch.
The subjects, presenting to the orthodontic clinic were assessed for eligibility according to the following inclusion criteria.

Inclusion Criteria:

1. Patients with age range from 15 to 25 (mean $=$ 19 years).

2. Single or double arch treatment.

3. Non-extraction treatment.

4. Presence of full complement dentition from first molar to first molar.

5. Good oral hygiene.

6. Healthy peridontium.

7. Anterior irregularity index greater than 5 .

8. No therapeutic intervention planned involving intermaxillary or other intraoral or extraoral appliances including elastics, lip bumpers, maxillary expansion appliances.

Patients who met the inclusion criteria were randomly assigned to the control and experimental groups. For all patients in both groups a rubber base impression (heavy and light) were taken to insure that fine details were recorded.

The rubber base impression were send to the manufacture (k-line lab) with the records and the treatment plane for each patient for aligner fabrication.

Once the aligners has been fabricated, each patients have received their aligners and instructed by the wearing instructions and time wearing protocol according to each group.

For both groups, the patients were instructed to change the aligner every 7 days. In the control group, the patients tried to wear the next aligner after 7 days but it was impossible to set the next aligner in all patients of the control group. 
In the experimental group, the patients tried to wear the next aligner after 7 days and all patients in this group can wear the next aligner easily after 7 days.

In the control group, the patients were tried to wear the next aligner on every day (on day 8, 9, 10 , $11,12,13)$ but the next aligner can't be changed before the day 14. For the control group, the time of aligners wearing was the same time instructed by the manufacture $($ mean $=14$ days) for each aligner.

The time the subjects receive their first aligner was recorded. The alignment of the teeth was clinically checked using a periodontal probe at every appointment and an impression was taken and poured for follow up and measurement on dental cast after each aligner. For the experimental group the time of wearing is reduced by half the time that instructed by the manufacture for each aligner (mean $=7$ days). The patients at this group were wear the first aligner the same time after the piezotome -corticision surgery.

\section{Piezotome-corticision procedure:}

Patients underwent the piezotome-corticision procedure at the Orthodontic Clinic, Al-Azhar University, Assuit.

Panoramic radiographs were utilized to assess the long axes of the teeth and root proximity prior to the procedure.

Local anesthetic was administered, then the depth of gingival tissue was determined using a periodontal probe.

A \# 15 Bard-Parker scalpel was used to make vertical incisions through the gingiva, $4 \mathrm{~mm}$ below the interdental papilla to preserve the coronal attached gingiva.

These vertical incisions were made interproximally on the labial aspect of the mandible through the gingiva and the underlying bone.
The incisions were $4 \mathrm{~mm}$ in length. After the incisions were made, the gingiva was slightly elevated laterally to visualize the bone and roots.

A piezosurgery knife, which is an ultrasonic microsaw, was used to create the cortical alveolar incisions to a depth of $1 \mathrm{~mm}$ within the cortical bone. The depth of the cortical incisions was limited to $1 \mathrm{~mm}$ for a safety margin in these severely crowded cases.

\section{Data collection:}

Little's irregularity index was used to measure the amount of crowding on the dental models at every appointment.

The proposed scoring method involves measuring the linear displacement of the anatomic points as distinguished from the clinical contact points of each tooth from the adjacent tooth anatomic point.

The sum of these displacements representing the relative degree of irregularity.

Perfect alignment from the mesial aspect of the left canine to the mesial aspect of the right canine would theoretically have a score of 0 , and with increased crowding represented by greater displacement and therefore a higher index score. Rather than measuring from contact points to ideal arch form or to another subjective point, the actual linear distance between adjacent contact points is determined. Such a measure represents the distance that anatomic points must be moved to gain anterior alignment.

\section{RESULTS}

The mean and standard deviation values were calculated for each group in each test. Data were explored for normality using Kolmogorov-Smirnov and Shapiro-Wilk tests, data showed parametric (normal) distribution. 
Repeated measure ANOVA was used to compare between more than two groups in related samples. Paired sample t-test was used to compare between two groups in related samples. Independent sample t-test was used to compare between two groups in non-related samples. Two-way ANOVA was used to test the interaction between different variables.

The significance level was set at $\mathrm{P} \leq 0.05$. Statistical analysis was performed with IBM ${ }^{\circledR}$ SPSS ${ }^{\circledR}$ Statistics Version 20 for Windows.

\section{Total Irregularity index:}

There was no statistically significant difference between (Control) and (Experimental) where $(p=0.221$

The highest mean value was found in (Experimental), while the least mean value was found in (Control) group.

\section{Total time of treatment:}

There was a statistically significant difference between (Control) and (Experimental) where $(p<0.001)$.

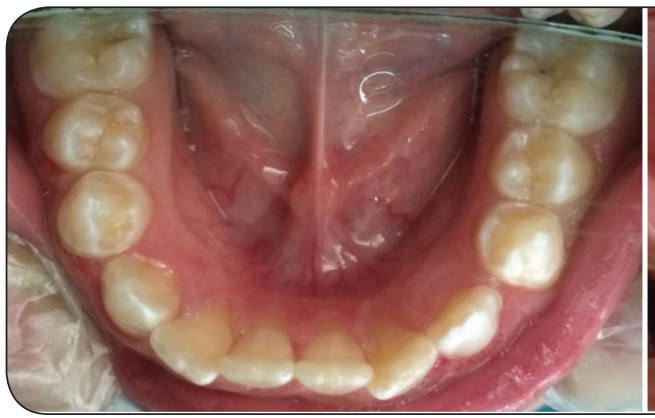

Fig. (1) A case representing the control group before and after treatment

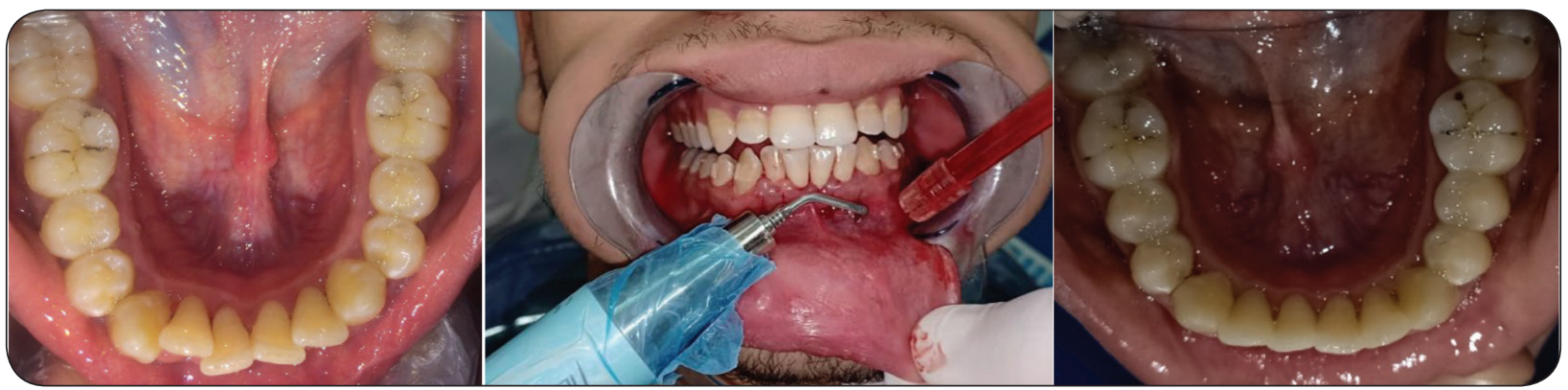

Fig. (2) A case representing the experimental group before, during surgery and after treatment 


\section{DISCUSSION}

Reduction of orthodontic treatment time is considered a goal in the management of malocclusions. ${ }^{9}$

Removable clear aligners have become a popular treatment choice for clinicians because of their esthetics, comfort, and better oral hygiene compared with traditional appliances, although their use is limited to selected cases.

Corticotomy has been claimed to reduce the treatment time because the resistance of the dense cortical bone to orthodontic tooth movement is removed. ${ }^{10}$ When responding to a traumatic stimulus, bony tissues initially undergo a biologic stage (RAP) characterized by a transient increase in bone turnover and a decrease in trabecular bone density. ${ }^{11}$

Based on recent studies, it seems that the length of the RAP is probably about 4 months. ${ }^{12}$ Considering this limit, in order to maximize the benefits of corticotomy in this case, we started treatment immediately after surgery.

Recent reports showed the results of selective corticotomy that was limited to the buccal and labial surfaces to reduce operation time and postoperative patient discomfort and to avoid the risk of violating vital lingual anatomy. ${ }^{13}$ Therefore, in this study, a selective corticotomy technique, limited to the buccal surfaces and without bone grafts, was used. The subjects selected for this study all had non-extraction treatment.

A substantial amount of patient cooperation was necessary; the patients were expected to comply with the instructions and keep their follow-up visits. The results of this study suggest that the overall treatment time needed to alleviate crowding in piezotome-corticision assisted and conventional orthodontics groups was significantly different which is consistent with previous studies that reported a drastic decrease in orthodontic treatment time in the piezotome-corticision group.${ }^{10}$
In our study, it was possible to complete treatment in approximately one- half the usual time using esthetic clear aligners. In this study, each aligner was in place for 7 days for the experimental group, rather than the usual 14 days for the control group, correcting the Class I malocclusion with moderate crowding.

In a previuos case report study ${ }^{14}$, it was possible to complete treatment in approximately one-third the usual time using esthetic clear aligners. In this case, each aligner was in place for 5 days, rather than the usual 15 days, correcting the Class I malocclusion with moderate crowding.

In the present study there was no statistically significant difference between (Control) and (Experimental) where $(p=0.221)$. The highest mean value was found in (Experimental), while the least mean value was found in (Control) group, and this can support the results of this study and encouraging the combined technique of clear aligner and corticision.

In this study we analyzed the rate of tooth movement at every point of time. the rate of tooth movement was great in the first month but still controlled by the range of aligner movements.

Previous study that combined a corticision group and a conventional orthodontic group concluded that the effect of corticotomies are limited to a maximum of 1-2 months in the canine model, suggesting that these effects may be limited to 2-3 months, during which 4-6 mm of tooth movements might be expected to occur. ${ }^{15}$

In another clinical investigation by Aboul-Ela, the rate of canine retraction was two times faster on the corticotomy side than on the control side during the first and second months and declined to 1.6 and 1.06 times in the third and fourth months, respectively. ${ }^{16}$

In the present study the rate of tooth movement is still controlled by the set of the aligner numbers 
which fabricated as a complete package from the start point of the study.

Currently, the long duration of fixed orthodontic treatment increases the risk of caries and external root resorption, decreasing patient compliance..$^{17}$

Finally, the limited deterioration of corticision may encourage the use of corticision as a time reducer in selected orthodontic cases, but the efficacy of the combined use of these techniques must be proven by other controlled clinical studies.

\section{REFERENCES}

1. Werner S, Julia H. Aligner orthodontics, Quintessence Publishing Co. Ltd, London, UK. 2016; 2: 28.

2. Rossini G, Parrini S, Castroflorio T, Deregibus A, Debernadi CL. Efficacy of Clear-aligners in Controlling Orthodontic Tooth Movement - A Systematic Review, Angle Orthod. 2014, Nov 20.

3. Lagravere MO, Flores-Mir C. The treatment effects of Invisalign orthodontic appliances: a systematic review. J Am Dent Assoc. 2005;136:1724-1729.

4. Pavoni C, Lione R, Lagana` G, Cozza P. Self-ligating versus Invisalign: analysis of dento-alveolar effects. Ann Stomatol. 2011;2:23-27.

5. Long H, Pyakurel U, Wang Y, Liao L, Zhou Y, Lai W. Interventions for accelerating orthodontic toot movement: a systematic review. Angle Orthod. 2013;83:164-171.

6. Nimeri $\mathrm{G}$, Kau $\mathrm{CH}$, Abou-Kheir NS, Corona R. Acceleration of tooth movement during orthodontic treatment--a frontier in orthodontics. Prog Orthod. 2013; 14:42.

7. Wilcko W, Wilcko MT. Accelerating tooth movement: the case for corticotomy-induced orthodontics. Am J Orthod
Dentofacial Orthop. 2013; 144(1):4-12.

8. Murphy KG, Wilcko MT, Wilcko WM, Ferguson DJ. Periodontal accelerated osteogenic orthodontics: a description of the surgical technique. J Oral Maxillofac Surg. 2009; 67(10):2160-6.

9. Cassetta M, Pandolfi S, Giansanti M. Minimally invasive corticotomy in orthodontics: a new technique using a CAD/ CAM surgical template. Int J Oral Maxillofac Surg. 2015; 44: 830-3

10. Wilcko W.M, et al. Rapid orthodontics with alveolar reshaping: two case reports of decrowding. Int J Periodontics Restorative Dent. 2001; 21(1): 9-19.

11. Baloul, S.S., et al., Mechanism of action and morphologic changes in the alveolar bone in response to selective alveolar decortication-facilitated tooth movement. Am J Orthod Dentofacial Orthop. 2011; 139(4): 83-101.

12. Sanjideh P.A, et al. Tooth movements in foxhounds after one or two alveolar corticotomies. Eur J Orthod.2010; 32: 106-13.

13. Germec, D, Giray B, Kocaderelli I, Enacar A. Lower incisor retraction with a modified corticotomy. Angle Orthod. 2006; 76:882-90.

14. Michele C, Federica A, Ersilia B. The combined use of corticotomy and clear aligners. Angle Orthod. 2015.

15. Buschang PH, Campbell PM, Ruso S. Accelerating tooth movement with corticotomies: is it possible and desirable? Semin Orthod. 2012; 18:286-94.

16. Aboul-Ela SM, El-Beialy AR, El-Sayed KM, Selim EM, El- Mangoury NH, Mostafa YA. Miniscrew implant-supported maxillary canine retraction with and without corticotomy-facilitated orthodontics. Am J Orthod Dentofac Orthop. 2011; 139:252-9.

17. Fisher MA, Wenger RM, Hans MG. Pretreatment characteristics associated with orthodontic treatment duration. Am J Orthod Dentofacial Orthop. 2010; 137:178-86. 


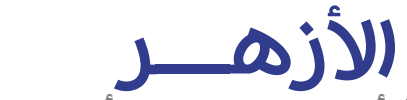 \\ مجلة أسيوط لطب الأسنان
}

النشر الرسمي لكلية طب الأسنان

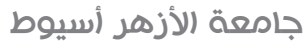

\section{تقييم فاعلية أجهزة التقويم الشفافة المدعومه جراحيا فس تسارع حركة الأسنان}

\author{
ابراهييم سعد عبد الغفار*, صالح انور السيد, مصطفى مجدى عبد المنعم \\ قسيم تقويه الفه, كليه طب الاسنان , جامعة الازهر, اسيوط , مصر
}

* البريد الالكترونى:

الملخص :

الهدف: هو تقييهم فاعلية أجهزة التقويم الشفافه المدعومهد جراحيا فى تسـارع حركة الأسـنان.

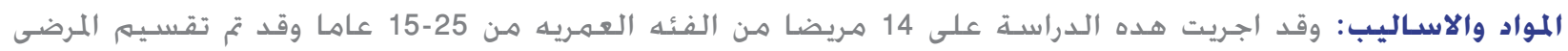

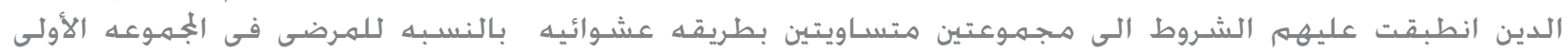

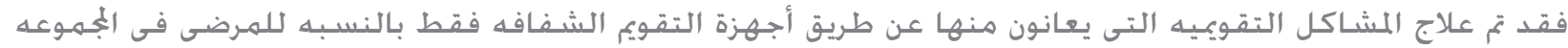

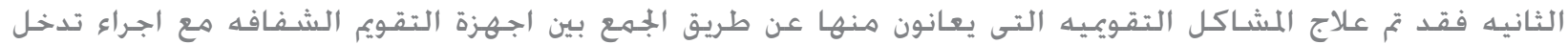

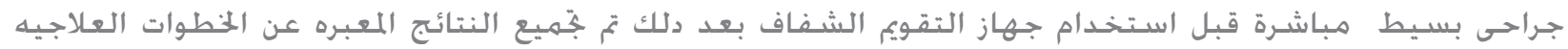

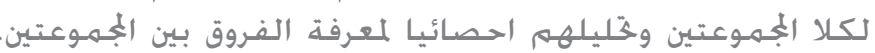

النتائج :وقد جاءت النتائج لتفيد بوجـود فروق معنويه احصائيا بين الجمهوعتين الخلاصه: حيث أفادت النتائج بامكانية

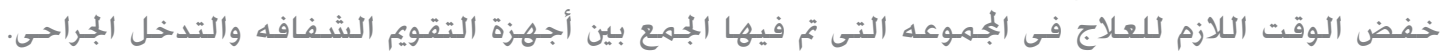
الكـلمـات المفتـاحيه: اجهزة التقويم الشفـافه، تزاحه الاسـنان، تقويم الاسـنان, حركـه الاسـنان، مدعوم جراحيا 